\title{
Public Acceptance on GST and Quality of Life
}

\author{
Arlinah Abd Rashid ${ }^{1}$, Azlina Hanif1', Rohana Kamaruddin² \\ ${ }^{1}$ Arshad Ayub Graduate Business School, Universiti Teknologi MARA, 40450 Shah Alam, Malaysia \\ ${ }^{2}$ Faculty of Business Management, Universiti Teknologi MARA, 42300 Puncak Alam, Malaysia \\ arlinah@salam.uitm.edu.my
}

\begin{abstract}
In Malaysia, the goods and services tax (GST) was implemented in 2015 as part of a tax reform program to generate a stable source of revenue. This study explores human behaviour towards GST, a week post-implementation. The partial least square (PLS) modelling was used to establish the relationship between acceptance, knowledge and feelings towards GST as well as the quality of life. There is a positive relationship between the antecedents and the quality of life. Acceptance of GST exerts a significant relationship towards feelings and quality of life in the future.
\end{abstract}

Keywords: GST, acceptance, knowledge, quality of life

eISSN 2398-4279 @ 2018. The Authors. Published for AMER ABRA cE-Bs by e-International Publishing House, Ltd., UK. This is an open access article under the CC BY-NC-ND license (http://creativecommons.org/licenses/bync-nd/4.0/). Peer-review under responsibility of AMER (Association of Malaysian Environment-Behaviour Researchers), ABRA (Association of Behavioural Researchers on Asians) and cE-Bs (Centre for EnvironmentBehaviour Studies), Faculty of Architecture, Planning \& Surveying, Universiti Teknologi MARA, Malaysia.

https://doi.org/10.21834/ajqol.v3i11.128 


\subsection{Introduction}

Goods and services tax (GST) or value added tax (VAT), is a consumption tax based on the value added concept. It is a multi-stage tax, imposed on goods and services at every production and distribution stage in the supply chain. Intermediaries in output and distribution process execute payment of tax in stages but the GST incurred on their business inputs is claimable from the government. To date, the highest rate being imposed is 17.5 percent in the United Kingdom. Other countries such as New Zealand and India, administer about 12.5 percent GST on most of the goods and services (Shamsuddin et al., 2014). Malaysia, which recently implemented the GST, fixed the rate at 6 percent.

Before the implementation of GST, Malaysia imposed the sales and services tax (SST), which contributed a mere 7.7 percent of total federal government revenue (Ministry of Finance, 2013). Thus, the GST was introduced to broaden the tax base and raise the government's revenue collection. This reform allows the country to reduce its dependency on oil-related revenue and income taxes, and ensure that the burden of tax can be equally shared between the services and manufacturing sectors.

In general, a positive outlook on Malaysia's economic growth is expected from the tax reform, attributable to several factors. There would be a reduction in business costs arising from the special schemes, credit offset mechanism and tax claims on business inputs system. The country's exports sector would also become more competitive since exports are zerorated. Also, the country's tourism industry is expected to gain a boost from the GST implementation, which may encourage higher tourism spending. Prices of certain goods and services might, in fact, be lower with GST implementation. These are due to the substitution of SST (which in the past amounted to a 15 percent rate) by the GST of 6 percent. The reduction in prices of several goods and services, tax exemption for many necessities and potential benefits such as the provision of better healthcare, infrastructure, and education, implies that Malaysians' quality of life is set to improve.

On another note, in the event of higher prices of certain goods and services due to GST, lower-income households would be most affected by the price shocks as they have minimal savings and a significant portion of their income is spent on indispensable items such as food and utilities. Having minimal savings, increases in prices would further affect their propensity to save, accumulate assets and to have better access to information technology as well as education, leading to lower quality of life.

Knowledge and acceptance of the pros and cons of GST implementation are critical in determining how the general public would perceive the tax reform and the impacts on the quality of life. Thus, the objective of the current study is to explore the relationship between acceptance and knowledge levels of Malaysians as well as their feelings towards the implementation of GST and the effect on quality of life, using the Partial Least Square approach. Findings from the study may indicate whether or not the government's efforts in communicating the importance of the GST are effective in enhancing the public's acceptance and knowledge regarding the tax reform. A significant positive finding towards the quality of life would exhibit that positive feeling towards the GST entail greater potential success in improving the quality of life in Malaysia. 


\subsection{Literature Review}

The World Health Organization Quality of Life (WHOQOL) project commenced in 1991 to construct an internationally comparable quality of life assessment instrument named WHOQOL-BREF. The instrument defines quality of life as:

"An individual's perception of his/her position in the context of culture and value systems in which they live in and in relation to their goals, expectations, standards \& concerns. It is a broad ranging concept incorporating, in a complex way, (1) the person's physical health, (2) psychological state, (3) level of independence, (4) social relationships, (5) personal beliefs and, (6) relationships to salient features of the environment".

Given the above definition, the current study believes that the GST implementation potentially affects one's perception of his/her quality of life through (6) i.e. one's relationships to salient features of the environment.

Consumers typically make their consumption choices not only based on price, but also quality, personal satisfaction, and other psychological needs that have consequences on happiness and well-being (Lau, Tam, and Heng-Contaxis, 2013). In the new tax environment, we would expect some adverse or positive consequences on one's happiness and well-being, affecting the quality of life, as certain goods would experience higher or lower prices after the implementation of GST.

Nevertheless, the quality of life can be improved if the government introduces offset packages such as affordable housing or efficient transportation system. For example, Singapore, which implemented GST since 1994, has added such package to improve the citizens' standards of living which include post-secondary education for students, GST credits, senior citizens' houses, rebates on utilities and public housing service, and cut in direct tax rates.

Several past studies have estimated the possible impacts of the GST or VAT implementation. Although there is a lack of studies on the effects of GST on the quality of life, in particular, we find such studies estimated the impacts of GST on households' income levels and tax burden. For example, Grady (1991) who used Statistics Canada's Social Policy Simulation Database and Model predicted that the proposed 7 percent GST in Canada would lead to an adverse impact on all family types and income levels. Moreover, families earning less than $\$ 30,000$ per annum will pay $\$ 20$ more in taxes on average, and 46 percent of such families will bear heavier the tax burden.

Rafaqat (2005) on the other hand, studied the incidence of VAT in Pakistan both in 19901991 and 2001-2002 periods, through the Household Integrated Economic Survey. Findings from the study suggest that after the reform, a higher proportion of the GST tax burden is borne by the poor and the middle classes compared to the richer group of the population. Additionally, the poor appeared to face a greater increase in the tax incidence plus declining expenditures.

Other studies, for example, Asafu-Adjaye and Mahadevan (2002) and Narayanan (2014), have estimated the impacts of GST on prices and welfare. Asafu-Adjaye and Mahadevan (2002) found that Australian consumers' purchasing power has deteriorated, and the GST did little to assist in the redistribution of consumption towards the low-income group. Narayanan (2014) believes that the GST implementation amidst an environment that is already 
inflationary in Malaysia would cause prices to rise. Elsewhere such as in European countries and South Korea, the impact of GST on price level is minimal as measures such as price and wage freeze, awareness campaigns; penalties and price monitoring were implemented simultaneously.

In Malaysia, studies examining consumers' attitude, perceptions, and acceptance towards GST were conducted before the implementation of GST. Palil and Ibrahim (2011) who administered a structured survey of the middle-income group residing in Klang Valley found that two-thirds of the respondents were not satisfied with the information the government provided regarding the GST and are not ready to support the implementation. Shamsuddin et al. (2014) found a similarly low level of awareness and acceptance of respondents on the implementation of GST unless there is sufficient information about it provided by the government. Both studies point out that the government should improve its communication channel so that more information is accessible, and greater understanding about the GST can be achieved, as also suggested by Ahmad, Ahmad and Alwie in a more recent study (2015).

Although the above studies seem to indicate that GST implementation has adversely affected the poor through an increase in price and a greater tax burden, these effects may be short-lived as the long-term effects of improvements in the quality of life as mentioned in the preceding discussion may outweigh the initial negative side-effects. From the above we could see that there are studies conducted for Malaysia to assess the feelings and acceptance towards GST. However, they were carried out prior to GST implementation and did not predict the effect on the quality of life. Therefore, given the above research context, we firmly believe that the proposed hypothesized model is novel as it attempts to explain the relationship between acceptance, knowledge and feelings towards GST and the effect on people's quality of life. The hypothesized model is as follows:

- H1: Acceptance has a significant effect on feelings towards GST

- H2: Knowledge has a significant effect on feelings towards GST

- H3: Feelings towards GST has a significant impact on quality of life

\subsection{Methodology}

A convenient random sampling of 730 respondents were interviewed a week after the GST implementation via structured questionnaires. The purpose of this exercise is to gather information on dimensions regarding their acceptance, knowledge, feelings towards GST and whether or not the GST affects their quality of life. The questionnaire included ten items measuring each of the dimensions. The respondents were mainly from Klang Valley.

The questionnaire was divided into seven sections. Section A identifies the background of respondents such as status, age, work sector and family members, Section B on the monthly expenses of a household for a particular segment of goods and services, and Section $C$ examines the general questions on GST. Meanwhile, section D uses a seven-point Likert scale to measure the acceptance level towards GST, Section E measures knowledge level of GST while Section F verifies respondents' feelings towards GST. The last section, Section 
F provides an overall evaluation of the quality of life after GST implementation.

To investigate the research model, we employed the PLS approach. Based on the twostage analytical procedures by Andersen and Gerbing (1988), we tested the measurement model as well as the structural model. The Smart PLS was used to analyse the data. Furthermore, Statistical Package for Social Sciences (SPSS) 20 version was used to import the data and also to explain the descriptive statistics. In order to test the significance of the path coefficients and the loadings, a bootstrapping method (500 resample) was employed to determine the significance levels.

\subsection{Findings and Discussions}

The demographic profiling of the respondents is described in Table 1.

Table 1: Demographic Profiling

\begin{tabular}{lcc}
\hline & Frequency & Percent \\
\hline Gender & 361 & 49 \\
Male & 369 & 51 \\
Female & & \\
Race & & \\
Malay & 406 & 56 \\
Chinese & 158 & 21 \\
Indian & 151 & 21 \\
Others & 15 & 2 \\
& & \\
Age group & & 40 \\
15-25 & 294 & 25 \\
25-35 & 180 & 16 \\
36-45 & 116 & 14 \\
45-55 & 99 & 6 \\
56-above & 41 & \\
Work Sector & & 19 \\
Public & & 27 \\
Private & 136 & 22 \\
Self-employed & 191 & 26 \\
Students & 161 & 7 \\
Unemployed & 192 & \\
Education & 50 & 27 \\
SPM \& lower & & 25 \\
Diploma & & \\
Bachelor & 200 & \\
Master & 181 & \\
PhD & 281 & \\
\hline
\end{tabular}

From the total of 730 respondents comprising of 361 males and 369 females, 40 percent are in the age group 15-25 years, and 25 percent are in the range of 25-35 years of age. About 16 percent respondents fall in the category of age between $36-45,14$ percent belong 
to the 45-55 age bracket, and the remaining 6 percent are 56 years and above. The race of the respondents is equally distributed based on Malaysia's population where Malays comprised of 56 percent of the respondents, Chinese 21 percent, and Indians 20.7 percent. Of the total respondents, a high composition of private sector workers and students is evidenced given that they total up to 53 percent of the sample. Self-employed respondents are the next largest composition, followed by those who work in the public sector and unemployed. As for the level of education, the majority hold a bachelor's degree. Meanwhile, 27 percent of the respondents have SPM and lower qualifications. Diploma and Masters' holders amount to 25 percent and 7 percent respectively.

In analyzing the measurement model, we need to assess the convergent validity that is the degree to which multiple items to determine the same concepts are in agreement. Hair et al., (2013) suggested considering factor loading, composite reliability (CR) and average variance extracted (AVE) to assess the convergent validity. For loading, the recommended value is 0.5 (Igbaria et al., 1995). In this study, the CR, which represents the degree to which the construct indicators specify the latent construct, varies from 0.899 to 0.944 . The AVE for knowledge of GST is 0.638 which is the lowest but above to the minimum cut-off value 0.5 (Hair et al., 2013).

Table 2: Results of Measurement Model

\begin{tabular}{|c|c|c|c|c|c|}
\hline Construct & Items & Loading & Alpha & $\mathrm{CR}$ & AVE \\
\hline \multirow[t]{7}{*}{ Acceptance } & D1 & 0.820 & 0.926 & 0.939 & 0.659 \\
\hline & D2 & 0.789 & & & \\
\hline & D3 & 0.837 & & & \\
\hline & D4 & 0.774 & & & \\
\hline & D5 & 0.864 & & & \\
\hline & D7 & 0.792 & & & \\
\hline & D8 & 0.836 & & & \\
\hline \multirow[t]{6}{*}{ Knowledge } & E1 & 0.862 & 0.892 & 0.913 & 0.638 \\
\hline & E2 & 0.783 & & & \\
\hline & E3 & 0.725 & & & \\
\hline & E4 & 0.847 & & & \\
\hline & E5 & 0.810 & & & \\
\hline & E6 & 0.758 & & & \\
\hline \multirow[t]{7}{*}{ Feelings } & F1 & 0.698 & 0.931 & 0.944 & 0.711 \\
\hline & F3 & 0.837 & & & \\
\hline & F4 & 0.846 & & & \\
\hline & F5 & 0.891 & & & \\
\hline & F6 & 0.883 & & & \\
\hline & F7 & 0.865 & & & \\
\hline & F8 & 0.866 & & & \\
\hline \multirow[t]{5}{*}{ Quality of life } & G1 & 0.828 & 0.860 & 0.899 & 0.641 \\
\hline & $\mathrm{G} 2$ & 0.817 & & & \\
\hline & G3 & 0.843 & & & \\
\hline & G4 & 0.806 & & & \\
\hline & G5 & 0.700 & & & \\
\hline
\end{tabular}

Another test of validity normally conducted in measurement model is discriminant validity. It indicates the degree to which items distinguish among the constructs or measure distinct 
concepts (Cheung, et.al, 2010). In other words, discriminant validity shows unrelated measures in reality are in fact unrelated. Table 3 shows the discriminant validity of this study where the square root of the AVE is higher than the correlations values in row and column. Based on the results in Tables 2 and 3 , the measurement model is accepted as it fits all the criteria of both convergent and discriminant validity.

Table 3: Discriminant Validity of Construct

\begin{tabular}{lcccc}
\hline & Acceptance & Feeling & Knowledge & $\begin{array}{c}\text { Quality of } \\
\text { life }\end{array}$ \\
\hline Acceptance & 0.812 & & & \\
Feeling & 0.653 & 0.843 & & \\
Knowledge & 0.130 & 0.094 & 0.799 & \\
Quality of life & 0.502 & 0.505 & 0.07 & 0.800 \\
\hline
\end{tabular}

In order to have confidence in the measures used, the study needs to test for the reliability of the measures. According to Sekaran and Bougie (2010), reliability measures the consistency of measurement of an instrument in whatever concept it is measuring. With reference to Table 2, all the alpha values for the constructs are greater than 0.6 with the minimum value of 0.860 for the quality of life. Thus, it can be concluded that the measurements are reliable.

Sang et al., (2010) stated that a structural model should indicate the causal relationship among constructs in a model (path coefficient and the $\mathrm{R}^{2}$ value). Both path coefficient (beta and significance) and the $\mathrm{R}^{2}$ value explain how the data supports the hypothesized causal relationship in the model (Chin, 1998). Table 3 and Figure 1 show the results of the structural model from the PLS output. The results indicate that the structural model explains 43 percent of the variance of feelings towards GST while only 26 percent describe the quality of life.

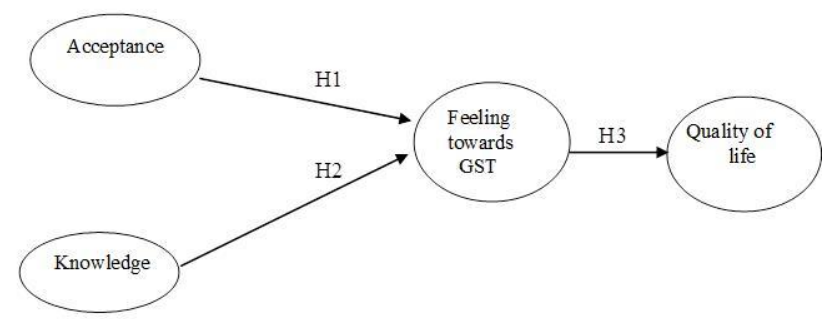

Figure 1: The Structural Model (Predictors and Outcome Feeling towards GST)

As exemplified by the findings, only acceptance is the most significant predictor of feelings towards GST. The effect of feelings towards GST and the impact to the quality of life is found to be statistically significant, and this suggests that people value the good intention of the government in implementing the GST. Table 4 summarizes these findings. 
Table 4: Summary of the Structural Model

\begin{tabular}{cccc}
\hline Hypothesized Paths & $\begin{array}{c}\text { Beta } \\
\text { Value }\end{array}$ & t-statistic & Decision \\
\hline H1: Acceptance-Feeling towards & 0.651 & $19.315^{\star * *}$ & Supported \\
GST & & 0.282 & Not Supported \\
H2: Knowledge-Feeling towards & 0.009 & $14.570^{* * *}$ & Supported \\
GST & 0.505 & & \\
H3: Feeling-Quality of Life & Note: ${ }^{* * *}$ indicates significance at 0.05 significance levels &
\end{tabular}

\subsection{Conclusion}

In summary, this study was carried out rigorously to achieve its objectives and the results obtained were reliable and valid. The empirical analysis using SEM-PLS yields valuable insights on the important predictors and outcome of feelings towards GST. The findings reveal that out of the three hypotheses tested; only two are substantiated. It is important to note that good feelings towards GST play an important impact towards public perceptions that GST could contribute to a good quality of life in the future. In addition, this study finds that acceptance is the only significant predictor of feelings towards GST. Surprisingly, predictor on knowledge, does not have significant effects on feelings towards GST.

Evidently, the research findings imply that relevant government or private agency should emphasize and prioritize their efforts and channel the resources towards improving the public acceptance and knowledge towards GST. They must ensure that the gains from GST will be reinvested in projects that would improve the quality of life through better health care, equal access to the education system, better infrastructure and greater accessibility to information technology. Moreover, workshops should be conducted to enhance public awareness and knowledge on GST, such as the amount collected and how it can help to improve the development of the country. The relevant authorities should study the outcome of GST implementation in other countries to educate the general public on what to expect and how to overcome any negative consequences.

The fact that the survey was conducted a week after the implementation of GST in Klang Valley, it would be necessary for future research to replicate this study after one year period. By doing so, it could enhance the validity and generalizability of the present findings. In addition, comparisons on the level of acceptance and knowledge on GST of Malaysian consumers in the short-term and long-term could be conducted to realize the time it takes for them to accept and understand the implementation.

\section{Acknowledgement}

The authors would like to thank Arshad Ayub Graduate Business School, Universiti Teknologi MARA for providing the financial support to conduct the research. 


\section{References}

Ahmad, R., Ahmad, R. \& Mohamad Alwie, S. (2015). Instilling Malaysian consumers' mind-set in accepting GST: An analysis on the effectiveness of communication used by the government, Innovation, Finance, and the Economy: Proceedings of the 13th Eurasia Business and Economics Society Conference, ed. Bilqin, M.H., Danis, H., Emir, E., \& Lau, C.K.M.

Anderson, J.C. \& Gerbing, D.W. (1988). Structural equation modelling in practice: A review and recommended twostep approach. Psychological Bulletin, 103 (3): 411-423.

Asafu-Adjaye, J. \& Mahadevan, R. (2002). The welfare effects of the Australian goods and services tax. The Singapore Economic Review, 47 (1), 49-63.

Cheung, C.M.K. \& Lee, M.K.O. (2010). A theoretical model of intentional social action in online social networks. Decision support systems, 49 (1): 24 -30.

Chin, W.W. (1998). The partial least squares approach to structural equation modeling. In Modern methods for business research, edited by G.A Marcoulides. London: Lawrence Erlbaum Associates, 295 -336.

Grady, P. (1990). An analysis of the distributional impact of the goods and services tax, MPRA paper no. 13144. Available at http://mpra.ub.uni-muenchen.de/13144. Accessed 8/10/2015.

Hair Jr, J.F., Hult, G.T.M., Ringle, C. \& Sarstedt, M. (2013). A primer on partial least square structural equation modeling (PLS-SEM). London: SAGE Publications, Incorporated.

Igbaria, M., Livari, J. \& Maragahh, H. (1995). Why do individuals use computer technology? A Finnish case study, Information and Management, 29 (5): 227 -238.

Lau, Z.Z., Tam, J. \& Heng-Contaxis, J. (2013). The introduction of goods and services tax in Malaysia: A policy analysis. Centre for Public Policy Studies, Asian Strategy \& Leadership Institute.

Ministry of Finance (2013). Estimates of federal government's revenue for the year 2013.

Narayanan, S. (2014). The impact of the goods and services tax (GST) in Malaysia: Lessons from experiences elsewhere (A note), Singapore Economic Review, 59 (2), June.

Palil, M.R. \& Ibrahim, M.A. (2011). The impacts of goods and services tax (GST) on middle-income earners in Malaysia, World Review of Business Research, 1(3), July, 192-206.

Rafaqat, S. (2005). Redistributive impact of GST tax reform: Pakistan, 1990 - 2001. The Pakistan Development Review, 44 (4), 841-862.

Sang, S. Lee, J.D. \& Lee, J. (2010). E- government adoption in Cambodia: a partial least squares approach. Transforming Government: People, Process and Policy, 4(2): 138-157.

Sekaran, U. \& Bougie, R. (2010). Research methods for business: A skill building approach (5 ${ }^{\text {th }}$ ed.) London: John Wiley and Sons Ltd.

Shamsuddin, A., Meor Ruslan, M.I., Abd Halim, A., Zahari, N. \& Mohamad Fazi, N. (2014). Educators' awareness and acceptance towards goods and services tax (GST) implementation in Malaysia: A study in Bandar Muadzam Sha, Pahang. International Journal of Business, Economics and Law, 4 (1), June. 
Rashid, A.A., et.al. / Asian Journal of Quality of Life (AjQoL), 3(11) May / Jun 2018 (p.125-134)

WHO Quality of Life-BREF (WHOQOL-BREF). Available

http://www.who.int/substance_abuse/research_tools/whoqolbref/en/ Accessed 10/10/2015.

at 